\title{
What are affecting choice of childbirth place among childbearing age women in western Ethiopia? A community-based cross-sectional study
}

Tariku Tesfaye Bekuma ( $\nabla$ tarii2007@gmail.com )

Wollega University https://orcid.org/0000-0002-7390-1788

Belaynesh Firrisa

Nekemte Specialized hospital

Melese Girmaye

Wollega University

Haile Bikila

Wollega University

Gemechu Kejela

Wollega University

\section{Research}

Keywords: Child birth place, Choice, Childbearing age women, Jimma Arjo

Posted Date: December 31st, 2019

DOI: https://doi.org/10.21203/rs.2.19761/v1

License: (c) (1) This work is licensed under a Creative Commons Attribution 4.0 International License. Read Full License 


\section{Abstract}

Background: Maternal death is the most extreme consequence of poor maternal health. More than 30 million women in developing regions suffer from serious diseases and disabilities due to inadequate care during pregnancy and delivery. Access to proper medical attention and hygienic conditions during delivery can reduce the risk of complications and infections that may lead to death or serious illness for the mother, baby, or both. In Ethiopia, the high maternal mortality rate with delivery by unskilled birth attendants shows low utilization of maternal health services.

Objective: This study was aimed to assess factors determining the choice of childbirth place among women of childbearing age in Jimma Arjo District.

Method A cross-sectional study design was conducted in Jimma Arjo District East Wollega Zone, Ethiopia, from March 20 to April 20, 2018. Multistage sampling technique was used to select a total sample of 506 participants. Data were collected using structured questionnaires to interview women of childbearing age. It was entered into Epi-Info and was exported to SPSS software version 20 for analysis. Data was checked for its completeness, cleaned, entered and analyzed accordingly. Bivariate and Multivariable data analysis was used to examine the association between dependent and independent variables.

Result: A total of 506 women participated in this study, giving a response rate of $97.8 \%$. This study has investigated that home delivery was found to be 200(39.5\%) whereas institutional delivery was $306(60.5 \%)$ in the study area. Factors found to be statistically associated with choice of institutional delivery at $p<0.05$ were; history of obstetric difficulties $(A O R=6,95 \% \mathrm{Cl}=(2.08,17.60)$ ), women educational status $(A O R=4.4,95 \% \mathrm{Cl}=(1.47,13.42))$, husband educational status $(A O R=4,95 \% \mathrm{Cl}=(1.43$, $11.60)$ ), having $2-3 \mathrm{ANC}$ Visits $(\mathrm{AOR}=4,95 \% \mathrm{Cl}=(1.95,8.52))$, and accessing vehicle transportation $(\mathrm{AOR}=$ $2.8,95 \% \mathrm{Cl}=(1.23,6.46))$.

Conclusion: Preferring health facility as birth place in this study seems relatively better compared to other studies. It's shown that attending secondary and more educational level in both mothers' and their husbands', history of obstetric difficulties, history of ANC attendance, having 2-3 ANC visits, and accessing facilty nearby have influenced mothers to prefer health institution as childbirth place. Therefore, any programs aimed at increasing choice of institutional delivery should first work on education, ANC follow up and transportation facilities in the study area.

\section{Plain English Summary}

Access to proper medical attention and hygienic conditions during delivery can reduce the risk of complications and infections that may lead to death or serious illness for the mother, baby, or both. There have been different interventions in Ethiopia like focused antenatal care, skilled attendants during delivery, family planning, and expansion and upgrading of comprehensive emergency obstetric care. However, the percentage of live births delivered by a skilled provider remained almost unchanged for a 
long period of time. The respondent child bearing women who were selected using a multistage sampling technique were interviewed at their home in this study.

This study has investigated that home delivery was found to be 200 (39.5\%) whereas institutional delivery was $306(60.5 \%)$ in the study area. The main factors found to be statistically associated with choice of institutional delivery at $p<0.05$ were; history of obstetric difficulties, women educational status, husband educational status, having 2-3 ANC visits and accessing vehicle transportation.

In conclusion, though it's still far below the WHO recommendation, preferring health facility as birth place in this study seems relatively better compared to other studies. Therefore, any programs aimed at increasing choice of institutional delivery should first work on the factors mainly; education, ANC follow up and transportation facilities in the study area.

\section{Background}

Globally, there were an estimated 289,000 maternal deaths in 2013, yielding a maternal mortality rate (MMR) of 210 maternal deaths per 100,000 live births. Developing countries account for $99 \%$ of the global maternal death (1) Maternal mortality is the highest by far in sub-Saharan Africa, where the lifetime risk of death from pregnancy-related conditions is 1 in 16, compared with 1 in 2800 in rich countries (2,3). In Ethiopia, according to EDHS 2011 and 2016, there are 676 and 412 maternal deaths for every 100,000 live birth respectively, and the infant mortality rate was 39 and 37 per 1, 000 live births respectively (4).

Maternal death is the most extreme consequence of poor maternal health. However, due to inadequate care during pregnancy and delivery or the first critical hours after birth, more than 30 million women in developing regions suffer from serious diseases and disabilities. These diseases and disabilities include uterine prolapse, pelvic inflammatory disease, fistula, incontinence, infertility, and pain during sexual intercourse. The majority of these deaths and complications could be avoided by access to basic maternity care and improved delivery care, which is supported by adequate medical and surgical cares (5).

Access to proper medical attention and hygienic conditions during delivery can reduce the risk of complications and infections that may lead to death or serious illness for the mother, baby, or both. In Ethiopia, the high maternal mortality rate with delivery by unskilled birth attendants shows low utilization of maternal health services which could be explained by low institutional delivery ranged from as low as $3.7 \%$ in Amhara to as high as $79 \%$ in the Capital city Addis, showing greater disparity existing within the country (6). The percentage of live births delivered by a skilled provider remained virtually unchanged for a period of 5 years after 2000, but increased substantially after 2005; from 6\% in the 2000 and 2005 EDHS to $10 \%$ in 2011 EDHS, and reached $28 \%$ in 2016 EDHS $(3,4,7)$.

As many studies conducted in the country indicated, factors including maternal age, parity, education and marital status, household factors including family size, household wealth, and community factors 
including socioeconomic status, community health infrastructure, residence, available health facilities, distance to health facilities, poor referral system and shortage of skilled attendants determine place of delivery and these factors interact in diverse ways in each context to determine the place of delivery (814) (Figure 1).

Maternal death has a large impact on the baby the mother is carrying, the health and wellbeing of the family, the community, and on the society in general. Each year, more than one million children lose their mothers due to maternal mortality. Evidence shows that children up to 10 years of age whose mothers died have a 3 to 10 time higher risk of dying within two years than children who live with their mothers (8). The WHO estimates that each year US $\$ 15.5$ billion is lost in potential productivity due to maternal and child death (9).

To reduce the burden of maternal mortality, many intervention strategies were developed by WHO and other organizations. Similarly, to reduce the high maternal mortality level, there have been different interventions in Ethiopia like focused antenatal care, skilled attendants during delivery, family planning, and expansion and upgrade of comprehensive emergency obstetric care. In addition to these interventions, the government of Ethiopia introduced health extension program to reach the community level and improve maternal health problems $(15,16)$.

In spite of the global and national efforts at reducing maternal morbidity and mortality through the safe motherhood initiative, there is no significant reduction in maternal morbidity and mortality in developing countries including Ethiopia $(17,18)$. Moreover, little has been studied about factors determining the choice of delivery place among women's of childbearing age, in Ethiopia in general and in the study area in particular. Therefore, the aim of this study was to elucidate the factors that determine women's choice of place of childbirth in Jimma Arjo district, Oromia regional state, Ethiopia.

\section{Methods}

\section{Study area and period}

Community based cross sectional study was conducted among 517 child bearing age mother who gave at least one child in Jimma Arjo district of East wollega zone, Western Ethiopia from March 20-April 20/2018. Jimma Arjo district is located at $379 \mathrm{Km}$ to west of Addis Ababa, the capital city of Ethiopia. According to Jimma Arjo District administration office report, the current (2017) population of Jimma Arjo district was estimated to be 114,175 . There are 20 rural kebeles and 2 town administration in the district. There is one district governmental hospital, four health centers and 20 health posts in the district. (Figure 1)

\section{Study design}

A community based cross-sectional study design was used. 


\section{Population}

All women of childbearing age (15-49 years) who reside in Jimma Arjo district were the source population and all women of childbearing age who had given at least one childbirth in the randomly selected kebeles of Jimma Arjo district were the study population for the study.

\section{Eligibility criteria}

Women of child bearing age who gave at least one childbirth within the two years preceding study period were included in the study while those childbearing age women who were severely ill at the time of data collection and who lived less than six months in the study area at the time of data collection were excluded from the study.

\section{Sample}

The sample size was determined using single population proportion formula with design effect of 2 . The estimated proportion was $18.8 \%$ which is percentage of women in Oromia who gave birth at health facilities in 2016 (4). Taking the assumptions in single population proportion formula with non-response rate of $10 \%$, a total of 517 women were interviewed in this study.

\section{Sampling techniques}

To get the study respondents, multistage sampling technique was used. There are a total of twenty rural and two urban kebeles in the district. From those kebeles, six rural and one urban were selected using simple random sampling method. The calculated total sample size was distributed across the selected kebeles proportionally to the size of the households within the respective kebeles. Then, systematic random sampling technique was used to select the actual study participants. First, initial household to be interviewed was selected randomly and, then, the subsequent households to be included in the study were selected systematically (Figure 2).

\section{Data collection and procedure}

A adapted structured questionnaire was prepared in English from different reviewed literatures $(29,32$, 36). The questionnaire was translated into Afan Oromo and retranslated back to English to ensure consistency. A pretest of the questionnaire was conducted among $5 \%$ of the total sample size outside of the study. The data was collected by 6 trained data collectors and supervised by two suppervisors.

\section{Variables}


Dependent variable: Woman's choice of birth place

Independet variables: Socio-demographic characteristics (age, maternal education, husband education, mothers occupation and husbands occupation, ethnicity and religions, income), distance from the facility, past obstetric history of the mother, parity, ANC follow up, obstetric difficulties, maternal decision to choose place of delivery and means of transportation.

\section{Operational definition}

Choice of birth place-The extent at which mothers who gave at least one child birth preceding study period preferred delivery place either institutional or home delivery due to factors contributing it.

Traditional medication- It is a treatment given culturally to delivery mothers at home to hasten child birth, to relief pain or to prevent complication of child birth or for others.

Antenatal care-Special care given to the pregnant mother prenatally (before birth) to prevent or early diagnosis of complication related to pregnancy, delivery and post partum.

Distance: It is measured in kilometers from home to the nearest health facility. According to

National standard distance $>5 \mathrm{~km}$ from home to health facilities are said to be far. It is measured with a statement, "What is the estimated distance from home to the nearby delivery institution?" With the option of below $2 \mathrm{~km}, 2-5 \mathrm{~km}$ and $>5 \mathrm{~km}$.

Women decision on birth place -Women's autonomy or power of women on ones own choice of delivery place. It is measured with a statement "Who decides on place of your delivery?

\section{Data processing and analysis}

After data collection was completed, it was entered into Epi-Info version 3.5.4 and exported to SPSS software version 20. It was checked for its completeness, cleaned and analyzed accordingly. Frequencies and percentages were used to describe the variables. The independent variables which was at $\mathrm{p}$-value < 0.25 with the dependent variable in bivariate analysis was included in the multivariate logistic regression model. In the multivariate analysis, the association of independent variable with the outcome variable was considered to be statistically significant at $p$-value of $<0.05$ with the corresponding $95 \%$ confidence interval.

\section{Data Quality management}

To assure the quality of data, two-day training was given for the six data collectors and one two supervisors on the study tools an how to collect the data. Pre-test of the questionnaires was done on $5 \%$ 
of the sample size and the appropriate correction was made before data collection. All collected data were checked for completeness, accuracy, and consistency by the supervisor every day and onsite close supervision and technical support was given by supervisors and principal investigator.

\section{Ethics and consent to participate}

Ethical clearance was obtained from the research and ethics review committee of Wollega University and official permission was granted from the Jimma Arjo district health office before data collection. Objective of the study was explained to in detail The respondents were reassured about the confidentiality of their response; their voluntarily participation was ensured; and right to take part or terminate at any time they wanted was respected. All the study participant women were above 18 years old and written informed consent was taken from all of them before involved in the study.

\section{Results}

\section{Socio-demographic characteristics of the respondents.}

A total of 506 women were participated in this study, giving a response rate of $97.8 \%$. Out of 506 respondents, $116(22.9 \%)$, were from urban and 390 (77.1\%) from rural kebeles. The age of mothers ranged from 21-45 years with mean and standard deviation of 31.6 $\pm 6.4(\mathrm{SD})$ years. Majority of the mothers were between $25-29$ years while above the age of 40 years were the least, $58(11.5 \%)$. Three hundred ninety-five (78.9\%) of respondents from the study area were married while 92(18.2\%) were divorced. Most of the respondents, 453 (89.5\%) of the respondents were Oromos in ethnicity. Regarding religioun, majority of participants, 308 (60.9\%) were protestants followed by Orthodox $182(36 \%)$.

Concerning occupational status of the respondents, majority 302(59.7\%) of them were housewives, followed by merchants $75(14.8 \%$ ) while the least, $6(1.2 \%)$ were students. Regarding educational status, $168(33.2 \%)$ of respondents able to read and write, 151(29.8\%) cannot read and write, whereas $61(12.1 \%)$ of them were diploma and above (Table 1).

\section{Past obstetric characteristics of the repondents}

Three hundred six (60.5\%) of the study subjects were between parity 2 and 4 , followed by parity greater than four $88(17.4)$ and the least $112(22.1 \%)$ were parity one. Three hundred sixty-two (71.5\%) of mothers had ANC follow up at health institution while 144 (28.5\%) of mothers had no ANC followup. The result showed that $85(16.8 \%)$ of mothers were prone to obstetric difficulties (Table 2 ).

\section{Women's choice of delivery place}


Of the total number of respondents, $200(39.5 \%)$ chose home whereas the rest respondents $306(60.5 \%)$ chose health institution as a birth place (Figure 3).

Pertaining to a decision on place of childbirth, $177(35 \%)$ of respondents replied that both husband and wife made a joint decision, 165(32.6\%) by their husband and 100(19.8\%) by women themselves (Figure 4).

In this study, it was reported that nearly half, $251(49.6 \%)$ of the respondents went on foot, followed by traditional transportation by mule/horse/karezza $91(18 \%)$ and vehicle 164(32.4\%) to reach their nearby facility. Concerning reasons for choosing institutional delivery, $161(54.5 \%)$ of them mentioned due to fear of complications, followed by informed to deliver in health institution 81 (34\%) while the least, $(8.2 \%)$ reported closeness of health institution to their home (Figure 5).

The respondents were also asked to justify why they chose home delivery and the reasons stated were, disliking behavior of health workers $74(34.6 \%)$, lack of money to pay for transportation and health service related costs $68(16 \%)$, and the least mentioned reason were having trust on TBA $58(15.4 \%)$ (Figure 6).

Regarding assistance of the last child born at health institution, 182(59.7\%) were assisted by midwives, followed by health officers $72(23.6 \%)$ and nurses $36(11.8 \%)$. From those mother who gave their last birth at home, 95(47.3\%) were assisted by a neighbor woman, 73(36.3\%) were assisted by mother in low and $26(12.9 \%)$ of them were assisted by their mother (Table 3 ).

\section{Factors affecting choice of delivery place}

In Bivariate logistic regression analysis, variables with $p$-value $<0.25$ which were added in the final multivariate logistic regression model were; age of respondents, residence, educational status, husband education, monthly household income, information of delivery in a health institution, ANC visits, obstetric difficulties, distance to the nearby health institution, means of transportation and time expent to reach health institution.

Accordingly, a multivariate logistic regression analysis result showed that mothers who completed secondary education were 4.4 times more likely to choose health institution as child birth place compared to those who cannot read and write $(\mathrm{AOR}=4.4(1.47,13.42)$ at $95 \% \mathrm{Cl})$. Similarly, women whose husband completed secondary education, were 4 times more likely to choose health institution as delivery place compared to a husband who cannot read and write, $(A O R=4(1.43-11.60)$ at $95 \% \mathrm{Cl})$. Compared to mothers who had first ANC visit, those mothers who had 2-3 times ANC follow up were also 4 times more likely to choose health institution as a delivery place $(\mathrm{AOR}=4(1.95,8.52)$ at $95 \% \mathrm{Cl})$. It was also found that a woman who have ever encountered obstetric difficulties and who had access to vehicles to reach health institutions were more likely choose institutional delivery with adjusted odds ratio of (6, $(2.08,17.60)$ at $95 \% \mathrm{Cl})$ and $(2.8(1.23,6.46)$ at $95 \% \mathrm{Cl})$ respectively (Table 4$)$. 


\section{Discussion}

This study revealed that 200 (39.5\%) of the total respondents, chose home delivery whereas the rest $60.5 \%$ chose institutional delivery. This finding is almost similar the study done in Jimma Zone, South West Ethiopia in which $35.38 \%$ of the mothers chose home delivery (19). However, it is far away when compared with EDHS 2016 where home delivery accounts 81.2\% (4). This could be resulted from the fact that EDHS is a large scale national data while this study was conducted only in single district.

The reasons mentioned for preferring home delivery were, smooth and short labor (32.7\%), uncomfortable behavior of health workers (34.6\%), no means of transportation (17.8\%) and no money to pay for transport and health service (16\%). Though the magnitude differs, similar reasons were also mentioned in the study conducted in Dega Damot woreda which were no money to pay for transport and health service 113(50.7\%), no means of transportation 134(60.1\%), and labor was smooth and short $106(47.5 \%)(20)$. This may ndicate that the reasons for preferring home delivery are common everywhere except some differences exist due to socio-economic, time and related differences.

Regarding factors affected choice of delivery place, in this study, it was found that both mothers with educational status secondary education and whose husbands with educational status of diploma and above were more than 4 times more likely to choose institutional delivery compared to those who cannot read and write. This is similar with the study done in Dega Damot district of Amhara and Ahferom district of Tigray, Ethiopia (20-21). This could be resulted from the reason that educated husband is expected to have knowledge and awareness about the advantages of institutional deliveries and seeking modern health care than those who are not.

It was also found that mothers who had 2-3 ANC visits during last pregnancy accounted 4 times more likely to choose health institution compared to women who had a single ANC visit. This finding is consistent with study finding of Sekela district in which mothers who have ever ANC visits during pregnancy were 4 times more likely to deliver in health facilities than those who did not have ANC visit during last pregnancy $(22,23)$. This indicates that the greater the number of ANC visits, the greater the opportunity to reinforce health messages which could result in better understanding and compliance by the women.

Concerning Obstetric difficulties, those mothers who faced difficulties were 6 times more likely to choose health institution compared to women who have not. This is inconsistent with the study done in Dega Damot woreda, West Gojjam zone could be due to variation in socio-demographic characteristics (20). Moreover, participants who had access to vehicles to reach health institutions were 2.8 times more likely to choose delivery at health institution than women who go on foot $(\mathrm{AOR}=2.8,95 \% \mathrm{Cl}: 1.23,6.46))$ which is consistent with other studies $(20,24)$ which revealed that poor transportation system pushes mothers towards home deliveries.

\section{Limitation of the Study}


The possibility of recall bias related to maternal age, a person assisting at health institution and obstetrical difficulties.

\section{Conclusion}

Preference of institutional delivery in this study seems relatively better compared to other studies. However, significant proportion of mothers are still giving birth to their babies at home. This study has shown that attending secondary and more educational level in both mothers and their husbands, history of obstetric difficulties, history of ANC attendance, having 2-3 ANC visits, and accessing vehicle for transportation have influenced mothers to prefer health institution as childbirth place. Therefore, the woreda education office should work on improving girl's education beyond the primary school level which will have a positive impact on preference of institutional delivery in the long run. All pregnant mothers should also be encouraged to have antenatal care attendance in nearby public health facilities using different means of information dissemination.

\section{Declarations}

\section{Ethics approval and consent to participate}

Ethical clearance was obtained from the Research and ethics review Committee of Wollega University and Official permission was granted from the district health office. Informed verbal consent was obtained from respondents before the data collection after explaining the objective of the study. To get full cooperation, respondents were reassured about the confidentiality of their response and was ensured their voluntarily participation and right to take part or terminate at any time they wanted. All the study participant women were above 18 years old and written informed consent was taken from all of them before involved in the study

\section{Consent for publication}

Not applicable.

\section{Availability of data and material}

Data will be available on request of the corresponding author.

\section{Competing interests}

There is no competing of interest

\section{Funding}




\section{Authors' contributions}

BF has participated in proposal writing, data collection process, data analysis, and interpretation, and report writing. In addition, TTB, MG, GK, and HB participated in data analysis, interpretation and preparing a draft of the manuscript. All authors have read, reviewed, and approved the final version of the manuscript.

\section{Acknowledgment:}

First, we would like to express our great gratitude towards the Wollega University Institute of health sciences, for allowing us to conduct this study in the community. We would also like to extend our heartfelt gratitude to Jimma Arjo district health office and the Woreda Administration Office for their cooperation during the data collection process. Lastly, we would like to thank the data collectors, supervisors and all study participants who took part in the study.

\section{Authors' Information}

All the authors are from Wollega University Institute of health sciences, while BF is currently is Senior Nurse at Nekemte Specialized Hospital.

\section{Abbreviations}

ANC: Antenatal Care

AOR: Adjusted Odds Ratio

CSA: Central Statistical Agency

EDHS: Ethiopian Demographic and Health Survey

MDG: Millennium Development Goals

MMR: Maternal Mortality Ratio

$\mathrm{MCH}$ : Maternal and Child Health

SBA: Skilled Birth Attendant

SDG: Sustainable Development Goals

SPSS: Statistical Product and Service Solution 
TBA: Traditional Birth Attendant

UNICEF: United Nations Children's Fund

WHO: World Health Organization

\section{References}

1. Adegoke A. and Vandenbroek, N. "Skilled birth attendance lessons learned," BJOG: An International Journal of Obstetrics \& Gynecology, 2009; 116(1): 33-40

2. Ohuwole D, An Overview of the maternal and newborn health situation in the African Region, in African health monitory. A magazine of WHO Regional Office for Africa.2004; 5: 2-4.

3. Central Statistical Agency and ORC Macro (2006) Ethiopia Demographic and Health Survey 2005: Addis Ababa, Ethiopia, and Calverton Maryland, USA.

4. CSA and ICF International Calverton. Ethiopia Demographic and health survey. Addis Ababa, Ethiopia; 2016.

5. Gabrysch S, Cousens S, Cox J, Campbell O: Distance and quality of care strongly influence choice of delivery place in rural Zambia: A study linking national data in a Geographic Information System. $J$ Epidemiol Community Health 2011, 65:A42-A42.

6. World Health Organization. Maternal mortality: Factsheet; 2010.

7. Central Statistical Agency Ethiopia, ICF International Calverton M, USA. Demographic Health Survey 2011, March 2012.

8. Say L, Raine R: A systematic review of inequalities in the use of maternal health care in developing countries: examining the scale of the problem and the importance of context. Bull WHO 2007, 85:812-819.

9. Gabrysch S, Cousens S, Cox J, Campbell O: Distance and quality of care strongly influence choice of delivery place in rural Zambia: A study linking national data in a Geographic Information System. $J$ Epidemiol Community Health 2011, 65:A42-A42.

10. Samai O, Sengeh P. Facilitating emergency care through transportation and communication, Bo, Sierra Leone. International Journal of Gynecology and Obstetrics 1997; 59(2): S157- S164

11. FMOH, UNICEF, UNFPA, WHO, AMDD. National Baseline Assessment for Emer- gency Obstetric and Newborn Care: Ethiopia, 2008. Final Report; 2009.

12. Ethiopia Demographic and Health Survey 2005. Addis Ababa, Ethiopia; Calverton, Maryland, USA: Central Statistical Agency, ORC Macro; 2006.

13. Muleta M, Fantahun M, Tafesse B, Hamlin EC, Kennedy RC. Obstetric fistula in rural Ethiopia. East Afr Med J 2007; 84(11):525-33

14. WHO, UNICEF, UNFPA. The World Bank and United Nation population division: Trends in maternal mortality: 1990 to 2013. Geneva: WHO; 2014. 
15. Federal Democratic Republic of Ethiopia Ministry of Health: Health Sector Development Program 2010: 48

16. Ndola Prata, Paige Passano, Amita Sreenivas \& Caitlin Elisabeth Gerdts: Women's Health: Maternal mortality in developing countries: challenges in scaling-up priority interventions. Women's Health (2010) 6(2), 311-327 ISSN 1745-5057.

17. WHO, UNICEF, UNFPA, the World Bank and United Nation Population Division. Trends in Maternal Mortality: 1990 to 2013.

18. United Nation and the African Union. Report on Progress in Achieving the Millennium Development Goals in Africa, 2013 Abidjan, Côte d'Ivoire; 2013.

19. Yegezu and Kitila, Assessment of Factors Affecting Choice of Delivery Place among Pregnant Women in Jimma Zone, South West Ethiopia: Cross-Sectional Study, J Women's Health Care 2014, 4:1

20. Sayih A. Factors determining the choice of delivery place among women's of childbearing age in Dega Damot Woreda, West Gojjam zone, Amhara regional state, Ethiopia, 2014

21. Weldearegay HG, Factors Affecting Choice of Place for Childbirth among Women's in Ahferom Woreda, Tigray, J Preg Child Health 2013; 2: 133

22. Shimeka A. Institutional delivery service utilization and associated factors among mothers who gave birth in the last 12 months in Sekela District, North West of Ethiopia, BMC Pregnancy and Childbirth $2012,12: 74$

23. Fira Abamecha Ababulgu and Tariku Tesfaye Bekuma, "Delivery Site Preferences and Associated Factors among Married Women of Child Bearing Age in Bench Maji Zone, Ethiopia," Ethiop Journal of Health Sciences, 2016;26(1), 45-54.

24. J. Lwelamira and J. Safari, "Choice of place for childbirth: prevalence and determinants of health facility delivery among women in Bahi District, Central Tanzania," Asian Journal of Medical Sciences, 2012; 4 (3), 105-112.

\section{Tables}

Table 1: Socio-demographic characteristics of respondents in Jimma Arjo district, Oromia, Ethiopia, 2018. 


\begin{tabular}{|c|c|c|}
\hline Variables & Frequency $(n=506)$ & Percent \\
\hline \multicolumn{3}{|l|}{ Age } \\
\hline $20-24$ & 172 & 34 \\
\hline $25-29$ & 123 & 24.3 \\
\hline $30-34$ & 88 & 17.4 \\
\hline $35-39$ & 65 & 12.8 \\
\hline$>=40$ & 58 & 11.5 \\
\hline \multicolumn{3}{|l|}{ Marital status } \\
\hline Married & 399 & 78.8 \\
\hline Single & 8 & 1.6 \\
\hline Divorced & 92 & 18.2 \\
\hline Widowed & 7 & 1.4 \\
\hline \multicolumn{3}{|l|}{ Residence } \\
\hline Rural & 390 & 77.1 \\
\hline Urban & 116 & 22.9 \\
\hline \multicolumn{3}{|l|}{ Religion } \\
\hline Protestant & 308 & 60.8 \\
\hline Orthodox & 182 & 36 \\
\hline Muslim & 16 & 3.2 \\
\hline \multicolumn{3}{|l|}{ Ethnicity } \\
\hline Oromo & 453 & 89.5 \\
\hline Amhara & 44 & 8.7 \\
\hline Gurage & 5 & 1.0 \\
\hline Tigre & 4 & 0.8 \\
\hline \multicolumn{3}{|l|}{ Occupation } \\
\hline House wife & 302 & 59.7 \\
\hline Governmental worker & 58 & 11.5 \\
\hline Mare chant & 75 & 14.8 \\
\hline Farmer & 50 & 9.9 \\
\hline
\end{tabular}




\begin{tabular}{lll} 
Daily labor & 15 & 3.0 \\
\hline Student & 6 & 1.2 \\
\hline Mother education & & \\
\hline Cannot read and write & 151 & 29.8 \\
\hline Read and write & 168 & 33.2 \\
\hline Primarily education & 36 & 7.1 \\
\hline Secondary education & 90 & 17.8 \\
\hline Diploma and above & 61 & 12.1
\end{tabular}

Table:2 Past obstetric characteristics of the respondents in Jimma Arjo district, Oromia, Ethiopia, 2018. 


\begin{tabular}{|c|c|c|}
\hline Variables & Frequency $(n=506)$ & Percent \\
\hline \multicolumn{3}{|l|}{ Gravidity } \\
\hline 1 & 92 & 18.1 \\
\hline $2-4$ & 316 & 62.5 \\
\hline$>4$ & 98 & 19.4 \\
\hline \multicolumn{3}{|l|}{ Parity } \\
\hline $0-1$ & 112 & 22.1 \\
\hline $2-4$ & 306 & 60.5 \\
\hline$>4$ & 88 & 17.4 \\
\hline \multicolumn{3}{|l|}{ ANC } \\
\hline Yes & 362 & 71.5 \\
\hline No & 144 & 28.5 \\
\hline Total & 506 & 100 \\
\hline \multicolumn{3}{|l|}{ No of visit of ANC $(n=362)$} \\
\hline 1 & 138 & 27.3 \\
\hline $2-3$ & 184 & 36.4 \\
\hline$>=4$ & 40 & 7.9 \\
\hline Total & 362 & 71.5 \\
\hline \multicolumn{3}{|l|}{ Ever obstetric difficulties $(n=506)$} \\
\hline Yes & 85 & 16.8 \\
\hline No & 421 & 83.2 \\
\hline \multicolumn{3}{|c|}{ Measure taken for Obstetric difficulties $(n=85)$} \\
\hline Nothing & 24 & 28.2 \\
\hline Visited health institution & 53 & 62.4 \\
\hline Massage, herbs, taking soft drinks & 8 & 9.4 \\
\hline
\end{tabular}

Table 3: Last delivery assistance among the women respondents, in Jimma Arjo district, Oromia, Ethiopia, 2018. 


\begin{tabular}{lll} 
Variables & Frequency $(\mathbf{n = 5 0 6})$ & Percent \\
\hline Assistant at home delivery & & \\
\hline Mother & 26 & 12.9 \\
\hline Mother- in-low & 73 & 36.3 \\
\hline Women from my neighbor & 95 & 47.3 \\
\hline TBA & 7 & 3.5 \\
\hline Assistant at HI delivery & & \\
\hline Mid wife & 182 & 59.7 \\
\hline Nurse & 36 & 11.8 \\
\hline Health officer & 72 & 23.6 \\
\hline Doctor & 15 & 4.9 \\
\hline Next delivery place & & \\
\hline Health institution & 326 & 64.4 \\
\hline Home & 180 & 35.6 \\
\hline Husband's choice of place of delivery & 298 & 41.1 \\
\hline Health institution & 208 & \\
\hline Home & & \\
\hline
\end{tabular}

Table 4: Multivariate analysis of selected variables (n-506) with women choice of birth place in Jimma Arjo district, Oromia, Ethiopia, 2018. 
Variables

Choice of birth place

$\mathrm{COR}, 95 \% \mathrm{Cl}$

AOR, 95\%Cl

Home, n HI n (\%)

(\%)

\section{Residence}

Rural

Urban

$\begin{array}{ll}189(48.5) & 201(51.5) \\ 11(9.5) & 105(90.5)\end{array}$

11

$9(4.68,17.23) \quad 2(0.46,7.99)$

\section{Educational status of the mother}

\begin{tabular}{|c|c|c|c|c|}
\hline Cannot read and write & 75(49.7) & $76(50.3)$ & 1 & 1 \\
\hline Read and write & $87(50.9)$ & $84(49.1)$ & $0.9(0.58,1.40)$ & )$^{0.8(0.36,1.86}$ \\
\hline Primary education (1-8) & $7(20.6)$ & $27(79.4)$ & $3(1.31,6.72)$ & $\begin{array}{l}\text { 1.8(0.57, } \\
5.93)\end{array}$ \\
\hline Secondary education & $22(24.7)$ & $67(75.3)$ & $3(1.71,5.43)$ & $\begin{array}{l}4.4(1.47 \\
13.42)\end{array}$ \\
\hline Diploma and above & $9(14.8)$ & $52(85.2)$ & $9(3.67-22.27)$ & $\begin{array}{l}3.8(0.92 \\
16.05)\end{array}$ \\
\hline \multicolumn{5}{|l|}{ Husband Education } \\
\hline Cannot read and write & $60(58.8)$ & $42(41.2)$ & 1 & 1 \\
\hline Read and write & $76(53.1)$ & $67(46.9)$ & $\begin{array}{l}1.6(0.91- \\
2.76)\end{array}$ & $2(0.77,5.50)$ \\
\hline Primary education (1-8) & $27(42.2)$ & $37(57.8)$ & $\begin{array}{l}2.5(1.29- \\
4.91)\end{array}$ & $\begin{array}{l}1.8(0.57 \\
5.60)\end{array}$ \\
\hline Secondary education & $25(24)$ & 79(76) & $\begin{array}{l}3.47(1.96, \\
6.15)\end{array}$ & )$^{4(1.43,11.60}$ \\
\hline diploma and above & 12(12.9) & $81(87.1)$ & $\begin{array}{l}12(5.73 \\
26.59)\end{array}$ & $\begin{array}{l}4(1.17 \\
13.38)\end{array}$ \\
\hline
\end{tabular}

Information about the benefit of delivery in health institution

\begin{tabular}{|c|c|c|c|c|}
\hline Yes & 185(38.8) & $292(61.2)$ & $\begin{array}{l}1.7(0.80- \\
3.59)\end{array}$ & $\begin{array}{l}3.8(0.98- \\
14.35)\end{array}$ \\
\hline No & 15(51.7) & $14(48.3)$ & 1 & \\
\hline
\end{tabular}

\section{ANC Visits (362)}


Obstetric difficulties ( like

prolonged labor, hemorrhage)

\begin{tabular}{|c|c|c|c|c|}
\hline Yes & $6(7.1)$ & $79(92.9)$ & $\begin{array}{l}11(4.80- \\
26.38)\end{array}$ & $\begin{array}{l}6(2.08 \\
17.60)\end{array}$ \\
\hline No & 194(46.1) & $227(53.9)$ & 1 & 1 \\
\hline \multicolumn{5}{|c|}{$\begin{array}{l}\text { Estimated distance to the nearby } \\
\mathrm{HI}\end{array}$} \\
\hline$<2 \mathrm{~km}$ & 15(13.9) & $93(86.1)$ & $4(2.22-8.09)$ & $\begin{array}{l}0.9(0.23 \\
3.94)\end{array}$ \\
\hline $2-5 \mathrm{~km}$ & $90(51.1)$ & $86(48.9)$ & $\begin{array}{l}0.8(0.60- \\
1.29)\end{array}$ & $1(0.81,3.03)$ \\
\hline$>5 \mathrm{~km}$ & $95(42.8)$ & $127(57.2)$ & 1 & 1 \\
\hline \multicolumn{5}{|l|}{ Means of transport } \\
\hline On foot & $113(32.9)$ & $230(67.1)$ & 1 & 1 \\
\hline Traditional transportation & $39(43.3)$ & $51(56.7)$ & $\begin{array}{l}1.5(0.90 \\
2.34)\end{array}$ & $\begin{array}{l}1.3(0.62 \\
3.09)\end{array}$ \\
\hline Vehicle & $48(65.8)$ & $25(34.2)$ & $3(1.92,5.26)$ & $\begin{array}{l}2.8(1.23 \\
6.46)\end{array}$ \\
\hline \multicolumn{5}{|l|}{ Time expent to reach HI } \\
\hline$<1 \mathrm{hr}$ & $8(11.8)$ & $60(88.2)$ & $\begin{array}{l}5.8(2.73 \\
12.54)\end{array}$ & $\begin{array}{l}2(0.44 \\
12.49)\end{array}$ \\
\hline $1-2 \mathrm{hrs}$ & 192(43.8) & $246(56.2)$ & 1 & 1 \\
\hline
\end{tabular}

Figures 


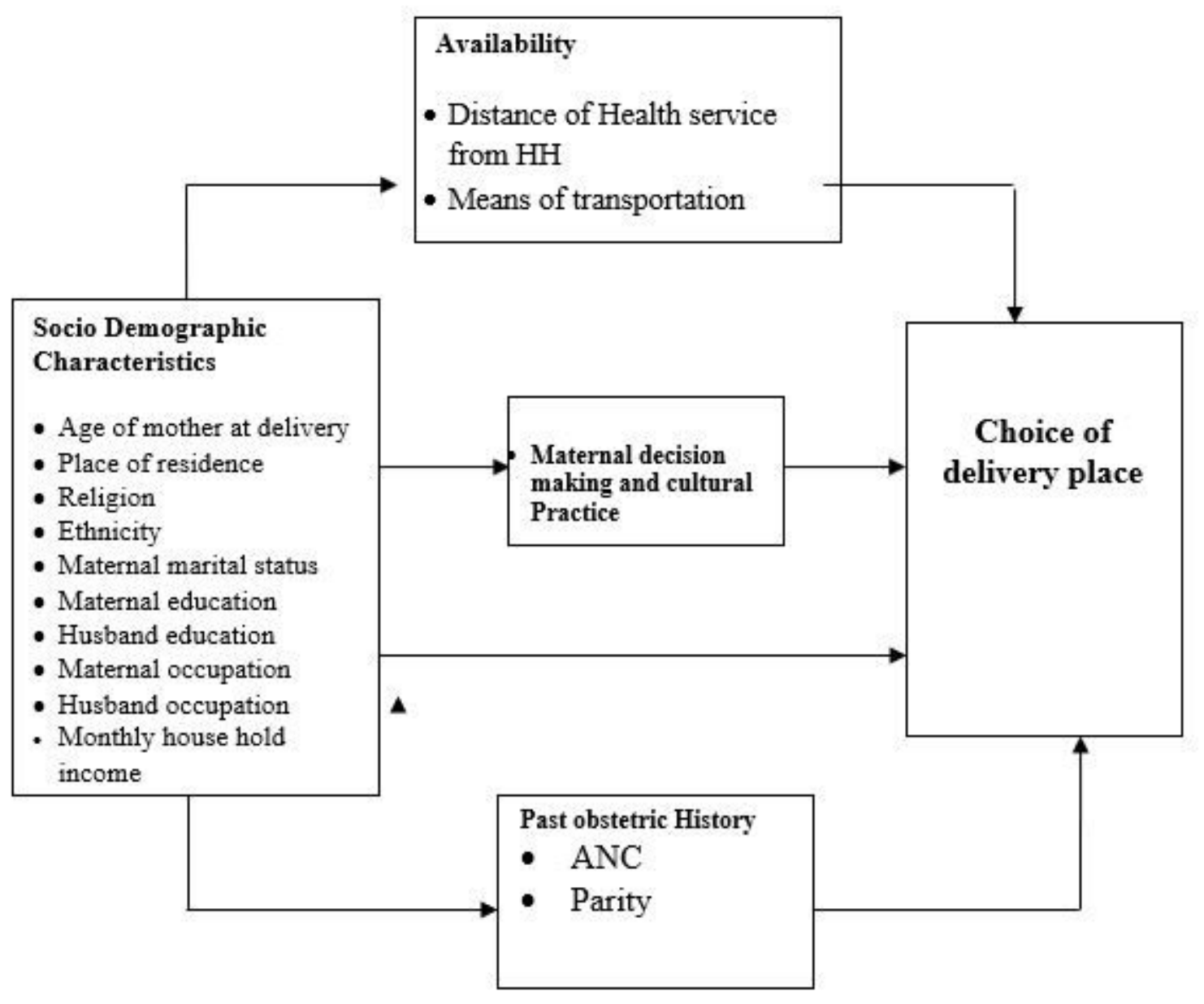

Figure 1

Conceptual framework for analyzing the determinants of maternal choice of birth place [Adapted from Sayih A, 2014] 


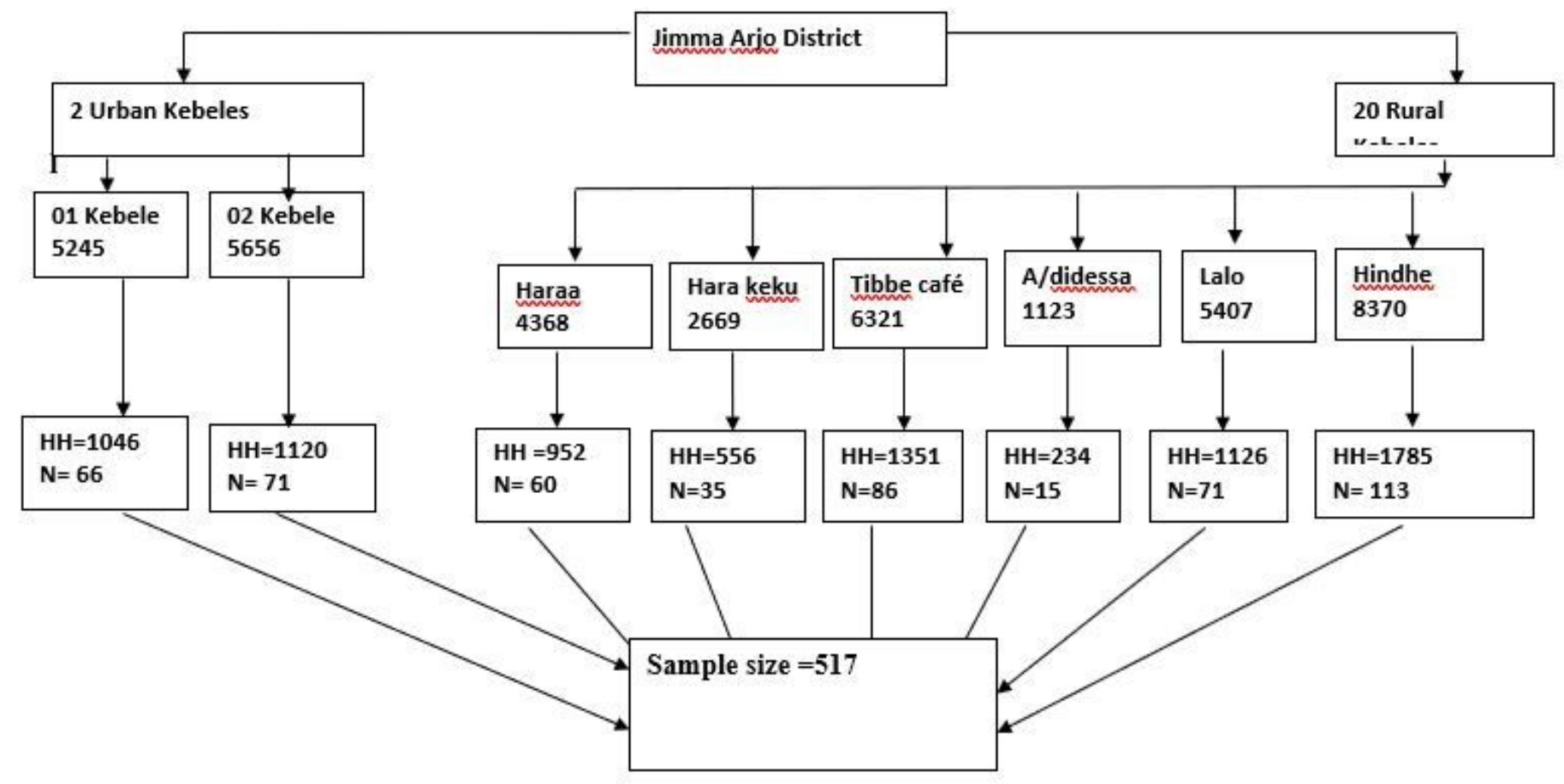

HH= House hold, $\mathrm{N}=$ No of sample size

\section{Figure 2}

Sampling technique for assessing the determinants of maternal choice of delivery place among child bearing age of Jimma Arjo district, Oromia Ethiopia, 2018

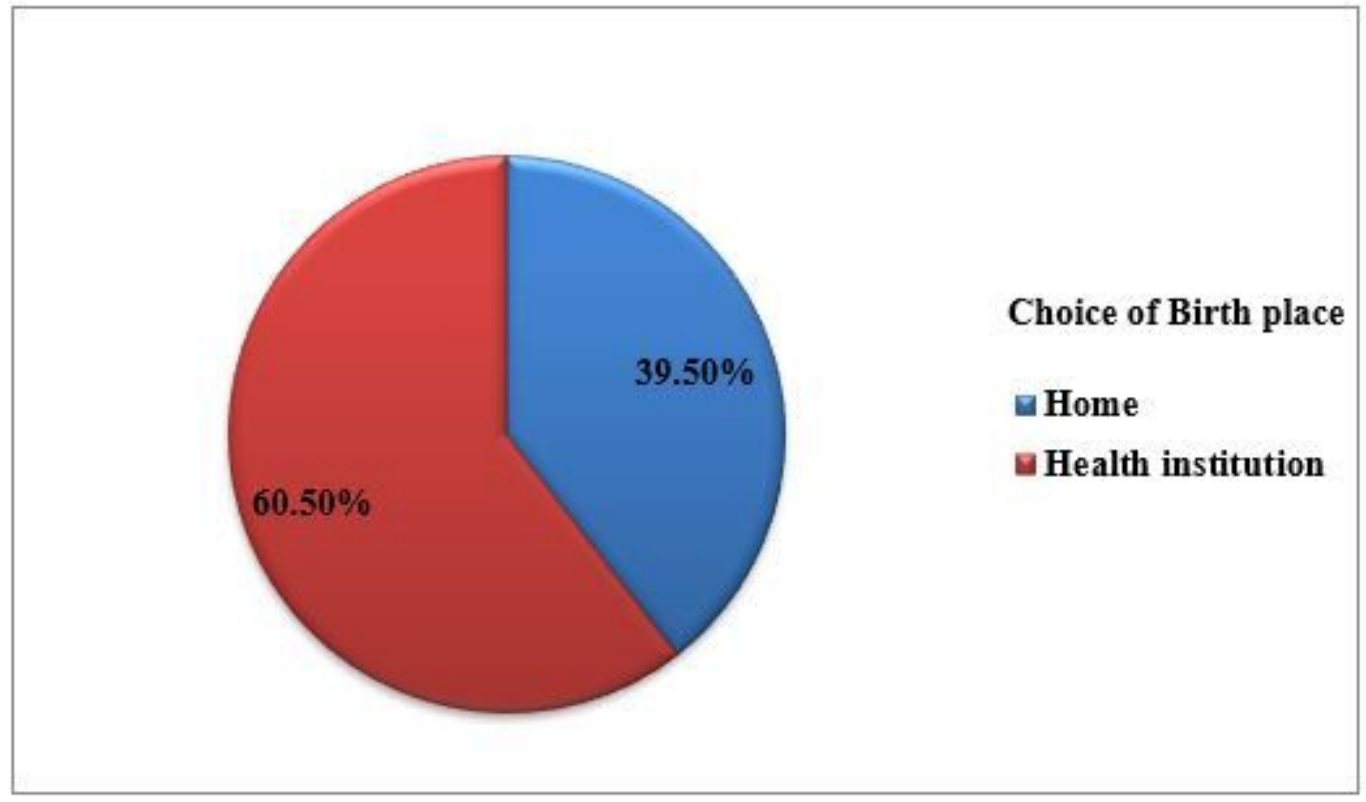

\section{Figure 3}

Maternal choice of delivery place in Jimma Arjo district, Oromia, Ethiopia, 2018 


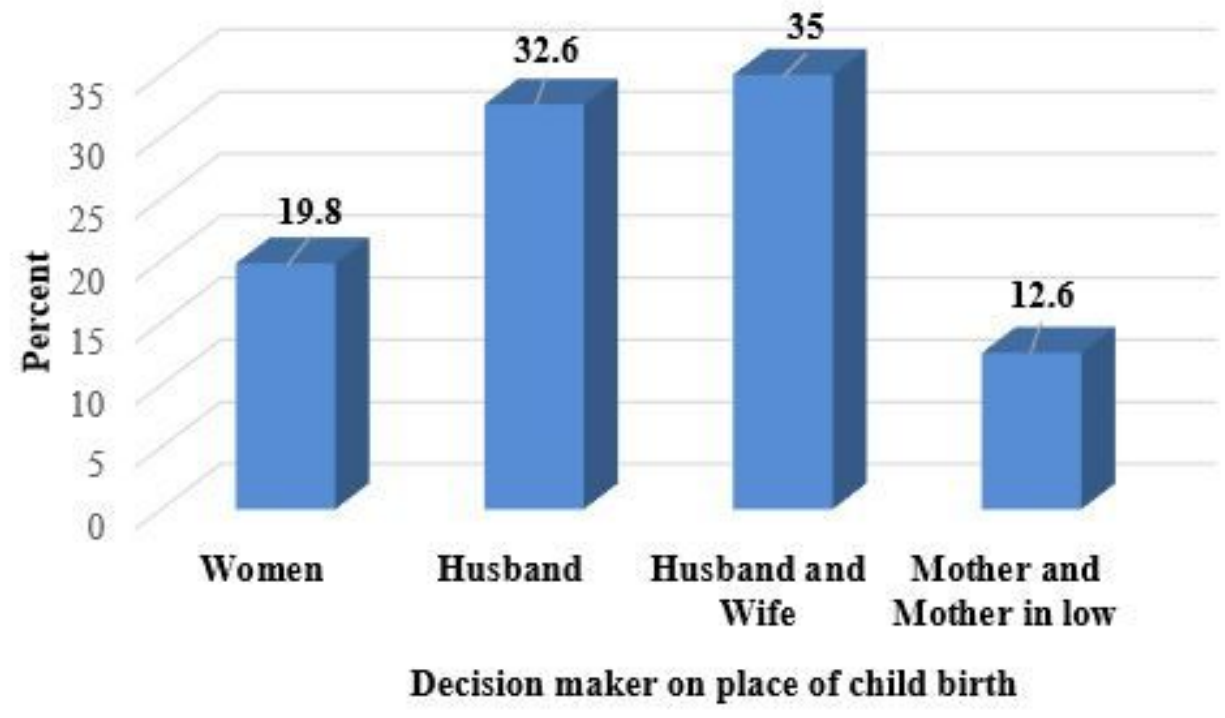

Figure 4

Women decision making power in Jimma Arjo district, Oromia, Ethiopia, 2018

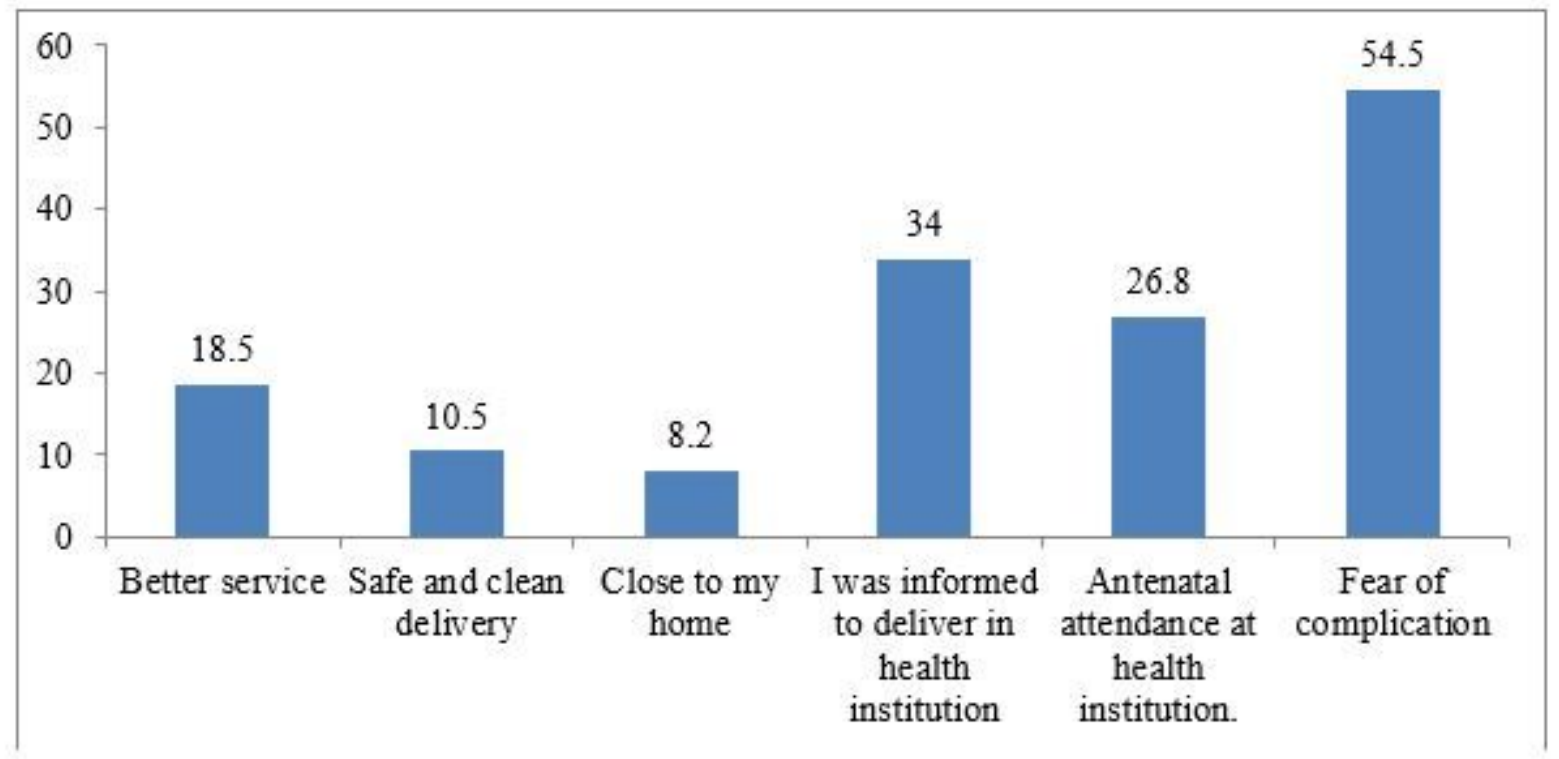

*More than one possible answer was used

Figure 5

Reasons for preferring institutional delivery $(n=306)$ in Jimma Arjo District, Oromia, Ethiopia, 2018 


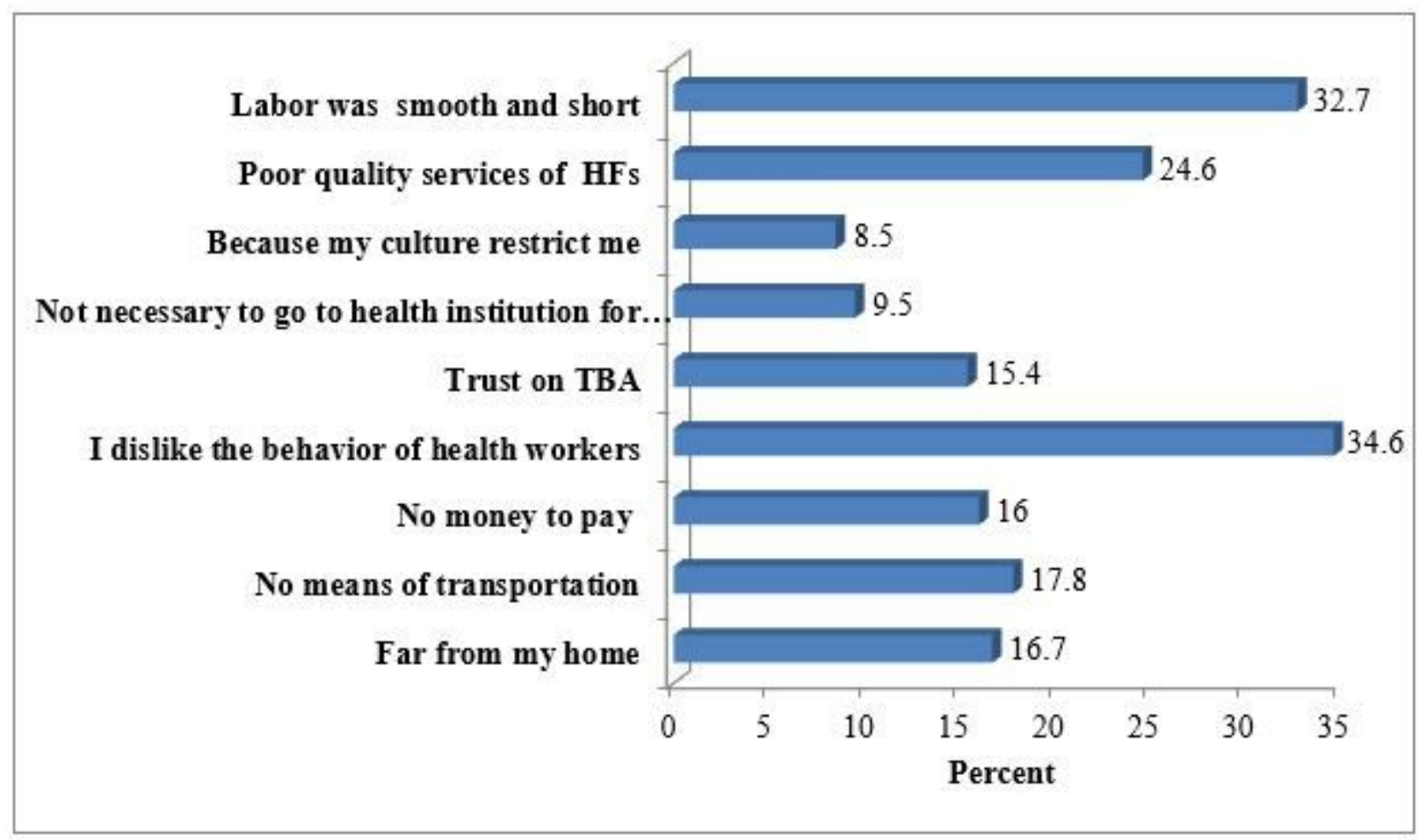

*More than one possible answer was used

Figure 6

Reasons for preferring home delivery $(\mathrm{n}=200)$ in Jimma Arjo District, Oromia, Ethiopia, 2018 